about the size and curve of that which flows from a healthy adult urethra. At first the source was supposed to be a vein and a clamp was applied but it proved to be an artificial channel hollowed out of the connective tissue and communicating with a reservoir deep in the pelvis. The muscular layer was next divided ancl we came immediately on the bladder which was undoubtedly distended but not so much as expected. The blood scemed all to come from the right side of the bladder and on passing the ingers in that direction down into the pelvis immerliately there welled up a large quantity of blood and urine, filling the line of incision and overllowing the abdominal wall, coming from a large cavity by the right side of the neck of the bladder. Quite one and a half pints of fluid had to be sponged out of the pelvis and after it seemed empty blood of a brighter tinge still continued to flow. On passing the hand down into the excavation it was clear that it was capable of holding the fluid that had already overflowed and as the bladder was still quite tense and full it was also plain that there was no rupture of that organ. At the bottom was felt the ischial or pubic ramus but quite denuded of all covering; the bare hard bone was there, but no line of fracture could be detected by the most careful searching with the finger nail. There is little doubt that when the perineum came in violent collision with the hard projecting earth the floor of the pelvis with the bladder was driven up into the abdomen and the right pubo-vesical ligament and all the soft structures were violently torn off the bone and forced up into the abdomen, and that at the same time the pudic vessels were torn across, and the urethra being also completely severed just at the tip of the prostate and behind the deep layer of the triangular ligament the blood and urine soon excavated for themselves a large chamber in this situation. Even here the pressure of the fluid was very high, for it had channelled out for itself a course through the muscular layer into the subcutanea, where it was found in the earlier part of the operation. As there was still bleeding going on the cavity was packed firmly with aseptic sponges. A small opening was next made in the bladder and with the finger insicle and a catheter in the urethra the instrument was ultimately insinuated successfully into the bladder and tied in. A piece of indiarubber tubing just fitting the resical opening conveyed the urine to a receptacle by the side of the patient; the wound was then partially closed and dressed and the patient was placed in bed.

On Jan. 14th the temperature was $101^{\circ} \mathrm{F}$. and the pulse was 118 . On the 22 nd the temperature reached $103^{\circ}$ and the pulse 104. The catheter was on the same day removed from the bladder as well as the tube from the vesical wound. There was considerabje pain in the urethra and the glands of the right groin swelled up. This was due to a little pus that had formed in the abdominal wall close to the incision. This was incised on the 24th. Some lymphangitis occurred in the thigh but was allayed by lotions of acetate of lead. After this all went well and the opening in the bladder closed on Feb. 19th. Nine weeks after the accident the patient was quite convalescent and his urethra so far has given no trouble. He is a young man of fine physique and there is little doubt that his youth and strength have borne bim over a very serious accident. Hull.

\section{PRE-MENSTRUAL PREGNANCY IN A GIRL AGED 13 YEARS.}

By AUGUSTUS W. ADDINSELL, M.B., C.M. Edin., M.R.C.P. LOND.,

PHYSICIAN TO THE LONDON TEMPERANCE HOSPITAL.

A GIRL, aged 13 years, was taken to the London Temperance Hospital by her mother early in January last suffering from abdominal pain and slight vaginal hæmorrhagic discharge. The breasts were well developed and contained milk. There was an abdominal tumour. The pubic hair was very slight in quantity. As vaginal examination was extremely painful an anæsthetic was given. It was found that an arm and the cord were presenting. There was no pulsation in the cord. Mr. T. G. Ward, the senior resident medical officer, performed version and removed a well-developed seven months child which showed no signs of life. Convalescence was without incident.

The interest of this case lies in the fact that impregnation took place before the outward signs of sexual maturity had manifested themselves. The eviclence of the mother had been carefully taken; the girl herself was very positive that "she had never seen anything" and remained unshaken when questioned by the medical registrar or by the sister of the ward in private conversation; she was at school and professed entire ignorance of her condition ; moreover, she positively denied any intimacy with man or boy.

There is nothing very remarkable in the age of this young mother. Plenty of cases of precocious maternity are to be met with. A girl, nine years old, gave birth to an infant in France; others of $11 \frac{3}{4}, 12$, and $12 \frac{1}{2}$ years respectively are recorded in this country but in these cases previous menstruation had been noticed. The testimony of the patient and her mother in this instance is so definite as to make it quite certain that the usual monthly flow had never taken place. After all, is this very wonderful? The signs of sexual maturity in the female are well known to be development of the mammary glands, growth of pubic hair, and finally menstruation. Whilst these are the outward signs of sexual maturity cellular activity within the ovary has been proceeding regularly since the birth of the individual. A very interesting and instructive contribution towards the study of the fate of the ovum and Graafian follicle in premenstrual life has been published by Dr. T. G. Stevens in vol. xlv. of the Transactionz of the Obstetrical Society for 1903. He there traces the history of the follicles and the series of changes they undergo, together with the fate of the ovum and its ultimate removal by the phagocytic agency of the cells of the membrana granulosa. This cellular activity within the ovary of the female is precisely similar to that which goes on within the testis of the male leading to the development of the spermatozoa.

Now sexual maturity depends for its onset upon a variety of causes, climate, race, nutrition, growth, \&c., but there is reason to believe that our remote ancestors matured sexually much earlier and were much more prolific; and that with the advance of so-called civilisation the recognised nubile age has been made later and later, until at the present time it presents a grave sociological problem in more than one European country. In Central Africa it is by no means an uncommon thing for a girl to become a mother before she has menstruated, and in certain districts of India where early marriages are common the same thing bas been recorded. Rachmakoff, a Russian physician, reports a case in a girl, aged 14 years. A traveller in the remoter regions of Australia told me of a case in his own camp of a girl, aged ten years, who had never menstruated and became pregnant. Metchnikoff in his book "The Nature of Man" quotes several cases also. In the warmer and Eastern climates then it would appear to be a well recognised fact and this doubtless because there is in those countries less sexual restraint, while in the West sexual maturity in both sexes comes later and when it does come environment, habit, training, and general oversight make early or precocious impregnation less probable, but that is all; precocity in the East is the rule, in the West it is the exception.

The life-history of the ovum and follicle in pre-menstrual life as traced by Dr. Stevens shows that maturity up to a point is constantly going on in those follicles which come to the surface, and when that point is reached retrograde changes take place in the infantile ovary. Now as the age of sexual maturity is being reached and as ovulation is regularly proceeding it is easy to see how impregnation might occur even though the outward and visible signs of sexual maturity be absent. The periodic occurrence of ovulation is most assuredly independent of menstruation and certainly precedes its initial onset and it is not difficult to see how the nervous and circulatory excitement attendant upon the act of coition may bring about the rupture of a ripe follicle and the resulting escape of the ovum.

Assuming the statement of this patient and her mother to be true (and there is no reason to doubt it, for every effort has been made to ascertain the exact facts)-viz., that she had never menstruated-then it is an added proof, were that needed, of the contention that ovulation and menstruation are not interdependent, though they may be coincidental.

There is something curiously akin to a pathological process in the menstruation of women. In every other instance discharges of blood, whether from the intestines, lungs, or kidneys, are evidence of disease. The analogue 
in the higher vertebrates is " heat," but in very few is this accompanied by a discharge of blood, and where there is a slight staining the proportion of red blood corpuscles to white is very small, as in those macaque monkeys observed by Heape of Cambridge. In the case of "Johannah," the famous chimpanzee, whose menstrual history I have recorded elsewhere, I made a careful microscopical examination of the menstrual discharge and satisfied myself that the red corpuscles were comparatively small in number, though enough to tinge distinctly and to stain red the monthly flow; still, all these were under the artificial surroundings of captivity. Not only the attendant pain and copious loss in woman but the general and nervous disturbances occurring at these times are suggestive of a departure from the originally normal line. The amenorrhcea accompanying lactation is often regarded by women as a welcome condition of security from impregnation. This we know to be an error, for ovulation is proceeding with its accustomed regularity and impregnation may, and often does, take place. Furthermore, the development of the endometrium every month may be safely regarded as the preparation of the uterus for the implantation of an impregnated ovum and the menstruation may be considered as evidence of a failure of these anticipations.

It is quite likely that primitive woman never menstruated, at any rate as we know menstruation to-day, and there is reason to believe that this phenomenon, this heritage of woman, of which she is not proud and for which she is not grateful, has assumed its present proportions as a result of the almost universal practice, begun in the earliest ages, of restraining the excessive uberty of our primeval ancestors.

Curzon-street, W.

\section{A CASE OF}

\section{CHRONIC INTESTINAL OBSTRUCTION WITH PERFORATION OF THE SIGMOID FLEXURE.}

\section{BY GEORGE A. CLARKSON, F.R.C.S. EYG.}

THE notes of the following case present one or two points of considerable interest. At the time of the first operation the history and the age of the patient led me to believe that I was dealing with a stricture of some part of the colon due to growth but the distension of the small intestine and cæcum was so great and the call for immediate drainage of the distended bowel was so urgent that no prolonged examination of the colon could be made. The subsequent sloughing and perforation of the sigmoid flexure probably occurred at the seat of obstruction, yet here no cause was obvious to account for the condition found. The gut, though in a condition little short of gangrene, was apparently not invaded by growth and the fact that no fæcal matter was found in it rather excluded the idea that retention of a scybalous mass of fæces at that point had given rise to inflammatory softening and perforation of its coats.

The patient, a woman, aged 52 years, had suffered from disease of the outer surface of the acetabulum for 12 years and the sinuses on the outer side of the right hip had healed after a free exploration and scraping in May, 1903. In the spring of 1904 she began to be subject to occasional attacks of vomiting, accompanied by abdominal pain, distension, and constipation, but these attacks were relieved from time to time by aperients and enemata. On May 9th she was seized with a severer attack than usual. The bowels were at first relieved and the sickness would stop for 12 hours at a time but invariably returned again. The patient was kept in bed, put on a fluid diet, and saline aperients and enemata were given with some result. A rectal examination revealed no stricture within reach of the finger nor could anything be felt through the abdominal walls to localise the seat of obstruction. On the 15th the symptoms became urgent, the vomiting being persistent and copious but not offensive in smell, the abdominal distension became very great, and there was obviously more or less complete obstruction. Enemata given through a long rectal tube produced no effect, so the patient was removed without delay to a surgical home. The opera. tion was carried out in the evening. The abdomen was opened in the middle line below the umbilicus. Enormous distension of the small intestine and cæcum was met with and as the transverse and descending colon appeared less distended and the indication to drain the bowel with as little delay as possible was urgent the wound was closed and another small incision was made over the cæcum, which was drawn out, opened, and a Patul's tube tied in. Following the operation there was a little vomiting of a stercoraceous character but the caccal opening gave great relief and the acute symptoms subsided. At the end of a fortnight the patient was able to be removed home. Enemata were subsequently given from time to time and occasionally brought away small scybalous masses.

On the afternoon of June 11th the patient was suddenly taker ill with intense pain in the left inguinal region and when I saw her was extremely collapsed, with drawn features, cold extremities, and thready pulse. Subcutaneous injections of strychnine with a little morphine were given and she gradually rallied, symptoms of an acute localised peritonitis quickly manifesting themselves. A diagnosis of intestinal perforation was made and on the 15 th an incision similar to that for inguinal colotomy was made over the area of pain and resistance. On opening the abdomen some very foul-smelling pus welled up and the abscess cavity having been thoroughly swabbed out the sigmoid flexure was seen plastered over with thick lymph and with a perforation on its anterior surface of the size of a shilling. The coats of the bowel were softened, black, and gangrenous and in bringing it forward it tore almost across. The wound was therefore enlarged in an upward direction and the bowel was slit up with scissors till its walls appeared unaffected by the changes below and would allow of its being stitched to the skin which was then done. The whole condition seemed to be an acutely inflammatory one. The abscess cavity was again swabbed out and then packed with iodoform gauze, an indiarubber tube of large calibre being passed into the colon.

The patient stood the operation well. The discharge was most offensive for some days but the cavity contracted quickly and at the end of a month the opening differed but little from an ordinary colotomy opening and it acted well. As the crcal opening became an annoyance to the patient when she began to get about again owing to the liquidity of the discharge, on August 11th, under ether, the mucous membrane was separated from the skin and the opening closed. At the time of writing (March, 1905) the patient finds no difficulty in controlling the artificial anus and she is able to get about out of doors and to resume her ordinary domestic duties at home.

Leicester.

\section{Clinital 睯otes:}

MEDICAL, SURGICAL, OBSTETRICAL, AND THERAPEUTICAL.

\section{A NOTE ON THE ABDOMINAL INCISIONS FOR THE EXPLORATION OF THE APPENDIX AND PER-} FORATED ULCER OF THE STOMACH.

\section{By Curnbert S. Wallace, M.B., B.S. LoNd.} F.R.C.S. ENG.,

SURGEON TO OUT-PATIENTS AT ST, THOMASS HOSPITAL; ASSISTANT SURGEON TO THE EAST LONDON HOSPITAL FOR CHILDREN.

The incision for exploration of the appendix.-The two abdominal incisions that are most in vogue for removal of the appendix-namely, that of McBurney and that through the rectus sheath-have their advantages and disadvantages. The McBurney incision is cramped and if difficulties are encountered gives poor access even if strongly spanned by assistants. It is, on the other hand, easily and quickly closed. The rectus sheath incision gives a good view and can be enlarged without difficulty to any extent; it is, however, often difficult to close owing to the tendency of the layers behind the rectus muscle to retract towards the iliac crest. The following modification seems to combine some of the advantages of both incisions. The rectus sheath is entered towards its outer side by the usual vertical incision. The muscle is then retracted inwards and the posterior wall of the sheath is exposed. As a rule two nerves are seen running transversely inwards about one inch apart. The mid-point between these is selected and the 